\title{
The American Society of Civil Engineers' Canon 8: Codifying Diversity as Ethics
}

\section{Dr. Canek Moises Luna Phillips, Rice University}

Canek Phillips (P'urepecha) is a postdoctoral research associate at Rice University in the Brown School of Engineering. Canek's research interests broadly relate to efforts to broaden participation in engineering. Currently, he is working on a project to improve mathematics education for visually impaired students.

\section{Dr. Yvette E. Pearson P.E., Rice University}

Dr. Yvette E. Pearson holds a B.S. in Civil Engineering and M.S. in Chemistry from Southern University and A\&M College and a Ph.D. in Engineering and Applied Science from the University of New Orleans. She is Associate Dean for Accreditation and Assessment in the George R. Brown School of Engineering at Rice University, a Program Evaluator for the Engineering Accreditation Commission of ABET, a registered Professional Engineer in Louisiana, a former Program Director in the Division of Undergraduate Education at the National Science Foundation, and a Fellow of the American Society of Civil Engineers (ASCE). Dr. Pearson currently chairs ASCE's Formal Engineering Education Committee, and is Vice Chair of ASCE's Committee on Diversity and Inclusion.

\section{Dr. Lisa M. Black, American Society of Civil Engineers}

Lisa M. Black, Ph.D. is Senior Manager of Diversity and Inclusion for the American Society of Civil Engineers, the nation's oldest engineering society representing more than 150,000 members. Dr. Black's responsibilities include developing, monitoring and evaluating programs, activities and products aimed at promoting full participation of underrepresented groups in the civil engineering profession. Through her work with ASCE's National Committee on Diversity and Inclusion, she provides leadership in all matters of diversity and inclusion within the civil engineering community and implements programs designed to advance awareness and recognition of the civil engineering profession, with a special emphasis on promoting civil engineering as an inclusive discipline. Prior to joining ASCE, Dr. Black held leadership roles in the public education sector where she served as Special Assistant to the Superintendent for Race and Equity in Madison Wisconsin and more recently as the Executive Director of Education and Training Programs for her husband's company, KLB \& Associates, Inc. She holds a B.A. in Sociology from North Carolina State University and both graduate degrees, an M.S. in Social Work and Ph.D., were earned from the University of Wisconsin-Madison.

\section{Mr. Quincy G. Alexander, American Society of Civil Engineers}

Quincy G. Alexander is a Research Civil Engineer at the USACE Engineer Research and Development Center. His research focuses on the development and implementation of structural health monitoring (SHM) tools and techniques used for evaluating the current conditions and predicting the future conditions of large civil infrastructure.

Mr. Alexander is also an active member of the American Society of Civil Engineers (ASCE), where he has served as a past branch president, section president, and regional governor. He is currently the chair of the ASCE Committee on Diversity and Inclusion, and concentrates on advancing the value of diversity and inclusion within the civil engineering community. 


\section{Codifying Diversity as Ethics: The American Society of Civil Engineers Code of Ethics Canon 8}

\section{Introduction}

Civil engineers in the US provide services that affect the lives of all of society such as assisting in the construction of roads, buildings, and dams. As a result, working for and with people from all walks of life is part of typical civil engineering practice. Canon 8 , a new ethic mandated by the ASCE in July 2017, crystallized the importance and necessity of diversity in the practice of civil engineers that all ASCE members must incorporate into their work. Canon 8 touches on several dimensions of diversity that members must be cognizant of in their work and is written as follows:

Engineers shall, in all matters related to their profession, treat all persons fairly and encourage equitable participation without regard to gender or gender identity, race, national origin, ethnicity, religion, age, sexual orientation, disability, political affiliation, or family, marital, or economic status.

a. Engineers shall conduct themselves in a manner in which all persons are treated with dignity, respect, and fairness.

b. Engineers shall not engage in discrimination or harassment in connection with their professional activities.

c. Engineers shall consider the diversity of the community, and shall endeavor in good faith to include diverse perspectives, in the planning and performance of their professional services [1].

Prior to Canon 8's adoption, violations related to unfair treatment and discrimination by ASCE members on the basis of identity did not have a clear mechanism through which to be addressed by the organization. Before Canon 8's adoption, could have been deemed problematic but ethical, or fallen under the purview of Canon 4's prohibition of workplace bullying, Canon 5's rule against biased critique, or Canon 7's call for relationships that are mutually beneficial [2]. With the passage of Canon 8, discriminatory behavior or practice no longer can fall within because of clear language that makes such practice a clear violation of ASCE ethical standards.

Canon 8's importance is grounded in the history of discrimination that was central to the segregation of the engineering profession in the $19^{\text {th }}$ and the first half of the $20^{\text {th }}$ century. In present legal terms, civil engineers are protected against discriminatory workplace practices based on identity by federal law [3] and Canon 8 might seem unnecessary couched in ahistorical terms. However, present legal protections are only a recent phenomenon in the history of the ASCE as well as several other engineering organizations that barred the entry of people based on their race or gender identities to help ensure that the profession would be vastly segregated to largely only include White men [4, 5]. Founded in 1852 by 12 White men [6], it took almost an entire century before Howard P. Grant, the first known Black ASCE member to join in 1948 [7]. It took more than 50 years before the first known female ASCE member Nora Stanton Blatch Barney in 1905 to join [5]. Canon 8's presence in the Code of Ethics is therefore quite reasonable because of a history within the civil engineering profession that clearly demonstrated the widespread acceptance of discrimination in the past that must not be forgotten. 
As written, Canon 8 codified the importance of an ethic of diversity in engineering along several dimensions that extends both to interactions between people as well as to practice that is cognizant of diversity. For example, whether or not civil engineers are cognizant, the work they do building and maintaining infrastructure carry with them implications for exacerbating or smoothing the effects racial inequity due to the racial segregation of US cities [8]. In the aftermath of Hurricane Harvey that devastated Houston, residents of Houston felt the effects of Harvey differently based on the segregated zip codes within the city. Primarily zip codes home to people of color were exposed to greater flood damage and environmental risks due to being segregated in areas of Houston that were lower in elevation and around high-pollution industry such as refineries [9]. In addition, a chilling image of nursing home residents stranded in a flooded lobby went viral that showed the lack of emergency preparation for people with disabilities and the elderly [10]. In rebuilding Houston and improving future emergency preparation, civil engineers will need to be cognizant of the social dimensions related to the effects of the hurricane or risk exacerbating the already present inequities within the city. Canon 8 instills the importance of socially conscious practice because it makes serving the entire public an ethical obligation. However, the language of Canon 6 does not clearly extend to violations of the fair treatment of people based on their identity, and therefore lacks the basic language necessary to act as a trustworthy standard. Additionally, Canon 8 creates a valuable mechanism through which people can understand that ignorance is not a valid argument to defend violations. For example, if someone committed bribery in direct violation of Canon 6, and used the defense of ignorance, members would understand this to be an unacceptable argument to justify the violation. Making the fair treatment of all people regardless of identity a canon means that members will, similarly, not be able to claim ignorance in justifying violations of fair treatment of all people and that violations falling under the classification of Canon 8 will follow the same type of organizational process of adjudication as would any other violation of the Code of Ethics.

The motivation of Canon 8 was to create a purview from which violations regarding discrimination on the basis of identity either through interaction or practice could be treated. In the following section, we speak in greater detail about the canon's guiding principles and cite two scenarios that would fall under the canon's purview to help illustrate the ways in which Canon 8 could be applied.

\section{Motivating Rationale}

The desire to lay the foundation for a profession ready for the full extent of society's diversity motivated the authors of Canon 8 to seek its addition into the ASCE's Code of Ethics. Prior to the drafting of Canon 8, key moments occurred that made the canon's necessity clear where ASCE members inappropriately and publicly made comments about people based on identity, yet there was the lack of a canon with clear language in place to prevent the behavior from occurring. ASCE members have historically used the Code of Ethics as the basis of a process to enforce professional norms [6]. For instance, when a member is in violation of one of the other 7 canons, the ASCE's Committee on Professional Conduct undergoes a process of review and to determine the severity and penalty for the violation [1]. However, without a canon that specifically guided ASCE members towards the fair treatment of all people, the organization had no clear process to reconcile violations. Furthermore, similar codes of ethics obligating civil engineers towards standards of the fair treatment of others regardless of identity already appeared in federal agencies that are major sites of engineering employment such as the US 
Dept. of Energy and US Dept. of Transportation as well as private enterprises such as AECOM and Bechtel, and engineering professional organizations such as the American Institute of Chemical Engineers, and the Institute of Electrical and Electronics Engineers [11-16].

The authors of Canon 8 developed the ethic as a way to demonstrate that the fair treatment of all people was not an individual-level choice in the ASCE, rather an organizational standard that makes it possible for the full participation of all members by creating a process where issues of discrimination can be handled within the organization. Furthermore, because ASCE canons apply to members at all times, members must follow Canon 8 both within and outside of official ASCE business to be considered in good standing with the organization.

Canon 8 was developed over a one-and-a-half-year period where its authors collaborated together to create its language in a way that clearly delineated the importance of diversity that was not covered through the language of the other canons. For instance, Canon 6, which broadly concerns violations of bribery, fraud, and corruption, is on one hand about conduct like Canon 8 [1]. However, the language of Canon 6 does not extend with violations extending the fair treatment of people based on their identity, and therefore lacks the basic language necessary to act as a trustworthy standard. Additionally, Canon 8 creates a valuable mechanism through which people can understand that ignorance is not a valid argument to defend violations. For example, if someone committed bribery in direct violation of Canon 6, and used the defense of ignorance, members would understand this to be an unacceptable argument to justify the violation. Making the fair treatment of all people regardless of identity a canon means that members will, similarly, not be able to claim ignorance in justifying violations of fair treatment of all people and that violations falling under the classification of Canon 8 will follow the same type of organizational process of adjudication as would any other violation of the Code of Ethics.

The motivation of Canon 8 was to create a purview from which violations regarding discrimination on the basis of identity either through interaction or practice could be treated. In the following section, we speak in greater detail about the canon's guiding principles and cite two scenarios that would fall under the canon's purview to help illustrate the ways in which Canon 8 could be applied.

\section{Case Studies Demonstrating the Necessity of Canon 8 Language}

The authors of Canon 8 developed and presented case studies to the ASCE board to illustrate the way the language of the canon and its specific guiding principles shape its application. The opening paragraph of Canon 8 specifies the dimensions of identity under the purview of the mandate. Furthermore, the three guiding principles (e.g. A-C) operationalize the way Canon 8 can be applied. One case study presented below, illustrated the way guiding principle " $\mathrm{C}$ " is operationalized through the experience of an ASCE member whose disability was overlooked in the design of a parking lot. The member's experience shows the way that the necessity of fair treatment of all people goes beyond discriminatory interactions and extends to inclusion of all people into the considerations of civil engineers in their practice as well.

When Regulations Fall Short: A Story of Inclusion 
Several years ago, my employer was undertaking a major construction project; it was a world-class research facility. The footprint of the structure took over one of two parking lots that had accessible parking close to my office. The second parking lot was closed to serve as a staging area for the construction project. I learned that the area was to be converted to green space post-construction in order to earn more points on the LEED application.

The nearest accessible parking to my building was now on the opposite side of a four-lane highway, which had a pedestrian bridge with elevators that worked intermittently. The second closest required a slightly uphill trek from the parking lot to my office building. I have a permanent disability, and the letter my doctor provided for me to obtain a handicapped parking placard stated that I cannot walk more than 250 feet at a time. In researching the Americans with Disabilities Act (ADA), I was surprised to learn that there is no rule about distance between accessible parking spaces and the buildings they serve. This is a clear example of the disconnect between those who are making rules/regulations and those they are intended to serve.

I wrote a letter to the facilities manager at my place of employment detailing the problem and stressing the need for the parking lot adjacent to my building to be re-opened after construction so that accessible parking would be available nearby. I made a compelling argument that I'm happy to say resulted in the parking lot being reopened. (Recently, the number of accessible parking spaces was doubled to meet the demand).

This is a very clear example of the importance of including perspectives of people with disabilities in design. The ADA and other regulations and codes give minimum standards that must be met. I can say firsthand that these often fall very short of meeting accessibility needs. Solutions are optimal when they employ principles of universal design and include perspectives of the users themselves (i.e., user-centered design). Those of us who have disabilities solve problems to overcome hurdles just to get through our daily routines. Imagine putting that kind of creative problem solving to use in civil engineering planning and design. Our built environment would be much better for everyone.

In the "Regulations" case, a scenario is scrutinized where civil engineers do not consider the entirety of the social implications of their design, negatively affecting people with disabilities. While the intentions of having a green space included in the construction of the building were well-intentioned in the sense of meeting LEED principles, the responsible civil engineers did not consider the lot's importance to people with disabilities who depended on the lot because of its safe and convenient position in relation to their workplaces. Destroying the parking structure would mean destroying a crucial resource for people with disabilities that would be detrimental to their accessibility to employment. Hence, while engineers may not have been willfully engaging in a discriminatory practice towards people with disabilities, to the ASCE member, the 
end effect of destroying the lot would constitute unfair treatment. Furthermore, the issue could have been entirely avoided if engineers had included the perspectives of people with disabilities in making their plans, the initial act of unfair treatment in the scenario.

The importance of the language in Canon 8 Principle $\mathrm{C}$ is to create a mechanism through which issues of unfair practice that affect people because of their identity can be dealt with so that civil engineering practice can change. Cases like the "Regulations" scenario have historically shown the blind spot of engineering in serving the public due to its lack of diversity along several dimensions of identity. For instance, [17] highlighted the poor design of the three-pointed seatbelt for pregnant woman, which often cannot protect the fetus even at speeds of $35 \mathrm{mph}$. Furthermore, as systems become more automated, designers implement their own blind spots into machines based on biased reference models that only account for limited segments of the population resulting in products like automatic lavatories that only recognized light hued skin colors [18]. Due to the lack of a canon that dealt with the lack of socially conscious design, an important mechanism was missing that could have served as a way to voice concerns about the constructions implications on people with disabilities. With the passage of Canon 8, the awareness of civil engineers will be heightened about the discriminatory implications of practice, which is one of the great benefits of having the canon as an organizational-level regulation.

The authors of Canon 8 presented a second scenario that illustrated the scenario of unfair treatment in workplace practice of a young African-American engineer that falls within the purview of guiding principles A \& B because of its themes of workplace practices that disrespect and discriminate along lines of identity.

\section{Unequal Treatment of a Minority Engineer}

The boss is walking around a potential hire for a senior level structural engineering position and begins to introduce the potential hire, we will call her Suzanne, to the group. My boss stops at "Sean's" desk, my equal (in terms of job classification and lesser in terms of structural bridge experience), and begins to introduce Sean by stating:

"Suzanne, this is Sean. He is one of my Structural EITs. He is a graduate of University A and has a Master's Degree from University B."

(Boss Moves to next coworker)

"This is Wyatt; he is also a structural EIT. He graduated from C University and is from ...

He splits his time between our Transportation group and Structures group. (Boss Moves to me) "This is Rodney. He is an EIT. He has worked for STATEDOT. He has worked in our other office and now he is here."

(Moves to the intern) 
"This is Allison. She is actually one of our interns at B University and she just found out she was accepted into graduate school."

Looking at this from a third-party perspective, one is left to question why Rodney was presented to Suzanne differently compared to his peers and the intern. What impression did this give Suzanne? She is left to question his qualifications and how he got here.

By the way, Rodney holds a Bachelor's Degree in Civil Engineering from D University and also a Master of Business Administration from B University, has 3.5+ years of experience as a structural engineer and will be sitting for the PE exam very soon.

In the "Unequal" scenario, the African American male civil engineer's account of the challenges he has faced on the job related to unequal treatment and discrimination related to Guiding Principles A and B. From the surface level, it appears that Rodney's boss was merely describing Rodney. However, the way Rodney is described compared to his colleagues shows unequal treatment given that Rodney has similar qualifications as his colleagues yet is spoken as a lesser. This type of interaction is a display of covert bias, also known as a "microagression [19]." The implications of the microaggression has an effect on how Rodney will be seen in his team that may lead to further discrimination. Suzanne may get the impression that Rodney is unqualified and may not seek to partner with Rodney on projects or be as collegial in sharing important work-related information.

Before Canon 8's passage, Rodney would not have had a way to help counter the discriminatory behavior brought forth because of the lack of widespread knowledge related to the existence and effects of microaggressions. While the term "microagression" is somewhat a misnomer in that the consequences of these aggressions are far from small in terms of detriment to career and well-being, they are made to seem small in the sense that their affects are often invalidated by those who do not recognize their harmful nature [19]. However, the language of Canon 8 explicitly states that these types of experiences must be dealt with as a matter of civil engineering practice, and as a result, it creates a space for issues that otherwise would not have been addressed.

\section{ASCE Reaction}

Following the passage of Canon 8, people gave feedback in on different channels of communication. On an ASCE page announcing the passage, comments ranged from supportive to critical. One supportive comment related to Guiding Principle C, where a member welcomed its implications in improving the practice of civil engineers. The member wrote:

I am proud to see ASCE adopting this new portion of the code to ensure that as we plan and design, we are more deliberate in considering the range of users. One example where we would have done better is in the design of bicycle facilities. For a very long time, they were not considered for their uniqueness and added to as a minor element to many roads, including those 
with speed limits exceeding $40 \mathrm{mph}$. Extensive research has shown that women are unlikely to use on-road bicycle facilities even when they are acceptable to male riders. (See research published by TRB committee $A B E 70$.$) When the planner/engineers involved in such projects included$ women, the conversation changed and now there are more hard barrier separated lanes and off road lanes. They not only serve the women riders better but open the facilities to use by many other populations (families with children, etc.) [20].

However, one member was initially critical of the implications of Guiding Principle $\mathrm{C}$ because they did not think that it was the direct responsibility of civil engineers to be aware of the implications of practice based on people's identity. Furthermore, they were critical of the political implications of principles A and B that having a public stance on issues of discrimination would have on ASCE. They wrote:

When I see things like “c.", I roll my eyes. It sounds like flaky, meaningless language. As a rational engineer, I find it mildly disgusting that such fluff has been approved by my professional society. If the persons who crafted and approved of this language want it to actually mean something, they should provide some examples of successes and/or failures. Not necessarily in the code of ethics, itself, of course (although more clarity and meaning would be appreciated and appropriate).

Examples for "a." are common knowledge (civil rights cases, discrimination lawsuits, persons of color or women being unfairly and irrationally disregarded or dismissed on the basis of race or gender). Same for " $b$." (sexual harassment lawsuits would be most common, women fired or otherwise coerced through working conditions when unwilling to engage in sexual acts with organizational superiors). Statements " $a$." and " $b$." are obviously appropriate and reasonable on their face. I don't have any idea how professional practice is supposed to satisfy the requirements in "c.", though.

Actually, I'm not sure that any of the statements should be part of our "professional code". The civil engineering profession clearly has a professional obligation to hold the safety of the public paramount. That is why we exist. We could not otherwise. These recently adopted statements feel more like they should be a personal pledge by members, and which members could choose to embrace in whole or in part. Is our profession now going to take a stand on which bathroom people should use? Should we advocate for such things on projects? Should such things not be worked out through legal channels (in which individual members are freely able to participate as private citizens, completely unrelated to their professional affiliation) [20]?

As we mentioned above, part of the reasoning for principle $\mathrm{C}$ is to bring to the fore that engineering practice is social and thus has social implications whether engineers are aware or 
not. The benefit of having a Canon that speaks to the importance of a Canon that enforces practice that serves everyone is the ability to say that ignorance is no longer an acceptable excuse. The comment drives home the point that not all engineers have received an education that makes the social implications of engineering apparent, which is something we hope to improve by talking about ways this can be done below.

\section{Teaching Inclusive Engineering Practice}

The newly published ABET Engineering Accreditation Commission (EAC) changes for the 2019-20 review cycle give several opportunities for faculty to develop and implement inclusive teaching practices and to teach their students to practice engineering in an inclusive way. This is accomplished in three distinct areas: definitions, Criterion 3 - Student Outcomes, and Criterion 5 - Curriculum.

First, in defining key terms programs and evaluators are to use in applying the criteria, ABET EAC has incorporated language that encourages diversity and inclusion. A few example definitions are (we added underlines for emphasis):

Complex Engineering Problems - Complex engineering problems include one or more of the following characteristics: involving wide-ranging or conflicting technical issues, having no obvious solution, addressing problems not encompassed by current standards and codes, involving diverse groups of stakeholders, including many component parts or sub-problems, involving multiple disciplines, or having significant consequences in a range of contexts [21].

Engineering Design - Engineering design is a process of devising a system, component, or process to meet desired needs and specifications within constraints... For illustrative purposes only, examples of possible constraints include accessibility, aesthetics, codes, constructability, cost, ergonomics, extensibility, functionality, interoperability, legal considerations, maintainability, manufacturability, marketability, policy, regulations, schedule, standards, sustainability, or usability [21].

Team - A team consists of more than one person working toward a common goal and should include individuals of diverse backgrounds, skills, or perspectives [21].

Second, many of the EAC Student Outcomes (SO) lend themselves well to addressing issues of diversity and inclusion in engineering programs (we added underlines for emphasis).

- SO2. an ability to apply engineering design to produce solutions that meet specified needs with consideration of public health, safety, and welfare, as well as global, cultural, social, environmental, and economic factors

- SO3. an ability to communicate effectively with a range of audiences 
- SO4. an ability to recognize ethical and professional responsibilities in engineering situations and make informed judgments, which must consider the impact of engineering solutions in global, economic, environmental, and societal contexts

- SO5. an ability to function effectively on a team whose members together provide leadership, create a collaborative and inclusive environment, establish goals, plan tasks, and meet objectives [21]

Finally, ABET EAC Criterion 5 - Curriculum includes requirements in four broad categories: (a) mathematics and basic sciences, (b) engineering topics, (c) broad education, and (d) culminating major design [21]. Categories (b) through (d) afford opportunities to teach students to practice engineering in an inclusive manner. For example, faculty members can incorporate principles of universal design into their courses to ensure students are aware of the importance of and are equipped to design for people with the widest range of characteristics possible. They can also train students on effective teaming, including the value of and respect for difference among team members. The "broad education component," which should "complement the technical content of the curriculum," could include courses offered in conjunction with social/behavioral sciences, humanities, and policy to help make strong connections between engineering and its societal impacts. The broadness of the component helps to encourage courses that are co-taught by faculty in engineering and other disciplines and taken by students in multiple disciplines and serves to help de-silo curricula across universities while supporting the development of students' abilities to work with team members from various backgrounds and perspectives. In the culminating major design experience, students can demonstrate their knowledge by engaging stakeholders with disabilities as they develop their work. In doing so, questions will likely arise as to the adequacy of existing standards and regulations, which may push students to think about going beyond minimum requirements when designing for accessibility.

Several great publications already utilize methods to connect the importance of diversity to engineering that can be used to teach to ABET EAC outcomes listed above. For example, [22] teaches thermodynamics by connecting energy to social problems like poverty and climate change and presents engineers with the ethical dilemmas at the center of the production of energy. [23] published an engineering checklist to guide engineering design that is more cognizant of the implications of gender. The checklist acts as a decision tree that engineers can follow when assessing the relevance of sex and gender in designs to help engineers design for all people. [24] presents a thorough guide of designing products with through the philosophy of Universal Design that is especially important in the creation of products that consider the needs of people with disabilities.

\section{Conclusion}

The passage of Canon 8 created a mechanism through which issues of discrimination in ASCE could be treated. However, more work is still required in ensuring that Canon 8 is an effective tool in enforcing the ethic of diversity in the society. The authors of Canon 8 realize that the next step after its passage is spreading awareness of the Canon to the rest of ASCE. To raise awareness, the authors plan to meet use collaborations with ASCE committees to inform members, creating a society-level award that would champion the ethic of diversity, and creating 
media featuring ASCE leaderships support of Canon 8 to show buy-in from the higher echelon of the organization. Also essential in the process will be to continue informing membership about the implications of Canon 8, how it would be applied, and why it was needed. While new, the motivations for Canon 8 were not. Engineering is about striving for constant improvement and Canon 8 serves that goal by making serving society at-large the end goal.

It is also important to note that while the adoption of Canon 8 marked a significant moment in the demonstration ASCE's commitment towards diversity, it is important to frame diversity, not just as a system where difference is tolerated on the grounds of what is acceptable in mainstream society today, but where changes that should be made, whether or not they are popular or challenge power, are made. One way to ensure that changes that bring about full inclusivity are made is by maintaining systems of accountability to check power. It is fully possible for institutions to champion diversity in statements but maintain the status quo because of the continued grip of old systems of power. Therefore, it is important to see accountability instituted so that structural changes that create barriers into civil engineering, like hiring practices that continually result in the lack of diversity, are changed. We also hope that the passage of Canon 8 leads to discussions about the implications of civil engineering practice in larger national and international issues, like the construction of the Dakota Access Pipeline, that is a clear violation of indigenous sovereignty or the potential building of a border wall between US and Mexico that is troubling both environmentally and politically. Even if these projects are legal, it does not mean that they are just. We hope that Canon 8 is part of what helps to stimulate wider discussions about engineering and power that find their way into engineering education and challenge all engineers to think of what a just engineering profession would be and go forth and make it a reality.

\section{References}

[1] American Society of Civil Engineers. (2017, December 28, 2017). Code of Ethics. Available: https://www.asce.org/code-of-ethics/

[2] T. Hoke. (2017) Abusive, Offensive Correspondence Leads to Suspension. Civil Engineering-ASCE, 2017. 40-41.

[3] Office of Federal Contract Compliance Programs. (2017). About OFCCP. Available: http://www.dol.gov/ofccp/aboutof.html

[4] J. Tang, Doing Engineering: The Career Attainment and Mobility of Caucasian, Black, and Asian-American Engineers. Lanham, MD: Rowman \& Littlefield Publishers, 2000, p. 242.

[5] R. Oldenziel, Making Technology Masculine : Men, Women, and Modern Machines in America, 1870-1945. Amsterdam, NLD: Amsterdam University Press, 1999.

[6] S. K. A. Pfatteicher, "Depending on Character: ASCE shapes its first code of ethics," Journal of Professional Issues in Engineering, vol. 129, no. 1, pp. 21-31, 2003.

[7] American society of Civil Engineers. (2017, January 12). Black History Month. Available: www.asce.org/black-history-month/

[8] M. A. Turner, R. Santos, D. K. Levy, D. Wissoker, C. Aranda, and R. Pitingolo, "Housing discrimination against racial and ethnic minorities 2012," Urban Institute, Washington, DC2013, Available:

https://www.huduser.gov/portal//Publications/pdf/HUD-514_HDS2012.pdf. 
[9] R. Bullard, "Hurricane Harvey: ZIP Code \& Race Determine Who Will Bear Burden of Climate Change," in Democracy Now!, A. Goodman, Ed., ed. Online, 2017.

[10] S. Millstein and S. Rosenbaum. (2017, August 28) 'Need Help ASAP.' The Story Behind the Photo of Nursing Home Residents Trapped in Hurricane Flood Water. Time. Available: http://time.com/4917743/la-vita-bella-nursing-home-dickinson-texas-photo/

[11] US Department of Energy. (2017, January 19). Ethics - The fourteen principles of ethical conduct for federal employees. Available: https://energy.gov/hc/ethics-fourteenprinciples-ethical-conduct-federal-employees

[12] US Department of Transportation. (2017, January 19). Ethics. Available: https://www.transportation.gov/ethics

[13] AECOM, "Code of Conduct," ed. Los Angeles, CA, 2014.

[14] Bechtel, "Code of Conduct," ed. Online, 2010.

[15] American Institute of Chemical Engineers. (2018, January 19). Code of Ethics. Available: https://www.aiche.org/about/code-ethics

[16] Institute of Electrical and Electronics Engineers. (2018, January 19). IEEE Code of Ethics. Available: https://www.ieee.org/about/corporate/governance/p7-8.html

[17] L. L. Schiebinger, I. Klinge, I. Sanchez de Madariaga, and M. Schraudner. (2011, January 10, 2018). Pregnant Crash Test Dummies: Rethinking Standards and Reference Models. Available: https://genderedinnovations.stanford.edu/casestudies/crash.html\#tabs-2

[18] M. Plenke. (2015) The Reason This "Racist Soap Dispenser" Doesn't Work on Black Skin. Mic.com. Available: https://mic.com/articles/124899/the-reason-this-racist-soapdispenser-doesn-t-work-on-black-skin\#.jDffaQfmX

[19] D. Solorzano, M. Ceja, and T. Yosso, "Critical Race Theory, Racial Microaggressions, and Campus Racial Climate: The Experiences of African American College Students," The Journal of Negro Education, vol. 69, no. 1/2, pp. 60-73, 2000.

[20] B. Walpole. (2017, January 20). Board Adopts New Canon for ASCE Code of Ethics. Available: http://news.asce.org/board-adopts-new-canon-for-asce-code-of-ethics/

[21] Accreditation Board for Engineering and Technology. (2018, January 15). Criteria for Accrediting Engineering Programs, 2018 - 2019. Available: http://www.abet.org/accreditation/accreditation-criteria/criteria-for-accreditingengineering-programs-2018-2019/

[22] D. Riley, Engineering Thermodynamics and 21st Century Energy Problems: A Textbook Companion for Student Engagement (Synthesis Lectures on Engineering, no. 3). 2011, pp. 1-97.

[23] L. L. Schiebinger. (2012, January 10). Engineering Checklist. Available: http://genderedinnovations.stanford.edu/methods/engineering_checklist.html

[24] P. J. Clarkson, R. Coleman, S. Keates, and C. Lebbon, Inclusive design: Design for the whole population. Springer Science \& Business Media, 2013. 